\title{
Cooperative effects of hepatitis B virus and TNF may play important roles in the activation of metabolic pathways through the activation of NF-kB
}

\author{
SHUANG WU ${ }^{1}$, TATSUO KANDA ${ }^{1}$, SHINGO NAKAMOTO ${ }^{2}$, XIA JIANG ${ }^{1}$, MASATO NAKAMURA ${ }^{1}$, \\ REINA SASAKI ${ }^{1}$, YUKI HAGA ${ }^{1}$, HIROSHI SHIRASAWA ${ }^{2}$ and OSAMU YOKOSUKA ${ }^{1}$ \\ Departments of ${ }^{1}$ Gastroenterology and Nephrology, ${ }^{2}$ Molecular Virology, \\ Graduate School of Medicine, Chiba University, Chiba 260-8677, Japan
}

Received February 22, 2016; Accepted June 8, 2016

DOI: $10.3892 / \mathrm{ijmm} .2016 .2643$

\begin{abstract}
Elevated levels of inflammatory cytokines such as tumor necrosis factor- $\alpha$ (TNF- $\alpha$ ) and interleukin (IL)- $1 \beta$ are often observed in the sera of hepatitis B virus (HBV)-infected patients. It is well known that these cytokines activate nuclear factor- $\kappa \mathrm{B}(\mathrm{NF}-\kappa \mathrm{B})$-signaling, and are associated with endoplasmic reticulum (ER) stress. We investigated whether HBV or HBV X protein (HBx) enhanced the activation of $N F-\kappa B$ in the presence of TNF and/or IL-1 $\beta$, and their effects on the expression of metabolic pathway-associated genes. We examined whether HBV or HBx enhanced cytokine-induced activation of NF- $\mathrm{NB}$ in hepatocytes, using a reporter assay, in the presence or absence of TNF and/or IL-1 $\beta$. The expression of insulin-like growth factor binding protein 1 (IGFBP1), one of the $\mathrm{NF}-\kappa \mathrm{B}$ target genes was also examined. The expression of metabolic pathway-associated genes in HepG2 and HepG2.2.15 cells in the presence or absence of TNF was evaluated by RT-qPCR. Human hepatocytes expressed TNF receptors and IL-1 receptors. NF- $\kappa \mathrm{B}$ was activated by cooperation between $\mathrm{HBx}$ and TNF in human hepatocytes. We observed IGFBP1 expression in HBV infection and that a number of metabolic pathway-associated genes were upregulated in HepG2.2.15 cells, compared with HepG2 cells with or without TNF treatment. We observed the cooperative effects of HBV and TNF which enhanced the activation of NF- $\mathrm{KB}$ as well as upregulated the expression of metabolic pathway-associated genes in hepatocytes. These effects may be important in the development of HBV-associated metabolic syndrome.
\end{abstract}

Correspondence to: Dr Tatsuo Kanda, Department of Gastroenterology and Nephrology, Graduate School of Medicine, Chiba University, 1-8-1 Inohana, Chuo-ku, Chiba 260-8670, Japan

E-mail: kandat-cib@umin.ac.jp

Key words: endoplasmic reticulum stress, hepatitis B virus, insulin-like growth factor binding protein 1

\section{Introduction}

Hepatitis B virus (HBV) infection is one of the major causes of hepatocellular carcinoma (HCC) $(1,2)$. Approximately 1.25 million individuals in the United States are chronically infected with HBV and approximately 43,000 new infections occur annually (3). Thus, HBV infection is a major health issues and understanding the pathogenesis of HBV as well as developing drugs for the management of HBV are of major importance (4).

In chronic hepatitis $B$ infection, the production of tumor necrosis factor- $\alpha$ (TNF- $\alpha$ ) by peripheral blood mononuclear cells (PBMCs) and the liver is increased $(5,6)$. Serum levels of interleukin (IL)-1 $\beta$, IL-6 and TNF- $\alpha$ are higher in patients with acute hepatitis B (7). These findings indicated that these cytokines may contribute to the elimination of HBV (8).

The higher expression of these pro-inflammatory cytokines is observed in adipose tissue and this expression is also associated with systemic inflammation and accompanying insulin resistance (9). In agreement with an association between inflammatory pathways and insulin resistance, a recent study of experimental endotoxemia demonstrated that acute inflammation induced by endotoxin administration induced systemic insulin resistance, suppressed insulin receptor substrate 1 (IRS1) and markedly induced suppressor of cytokine signaling proteins in adipose tissue, which was accompanied by the increased tissue expression of pro-inflammatory cytokines (10).

Insulin and insulin-like growth factor-1 (IGF-1) act as growth factors to promote cell proliferation and inhibit apoptosis (11). IGF-1 is involved in hepatocarcinogenesis $(11,12)$. IGF-binding protein 1 (IGFBP1) is one of the soluble proteins that regulates the activity of IGFs (13). The liver is the major source of IGFBP1 in non-pregnant humans (13). Higher serum levels of IGFBP1 are observed in liver cirrhosis and other liver diseases (13). IGFBP1 is also involved in human carcinogenesis $(14,15)$. Thus, insulin and IGFBP1 may be involved in the pathophysiology of liver diseases.

The activation of nuclear factor- $\kappa \mathrm{B}(\mathrm{NF}-\kappa \mathrm{B})$ in the cytoplasm results in translocation to the nucleus. This induces production of pro-inflammatory cytokines such as TNF- $\alpha$ and IL-1 $\beta$ (16). In the present study, we examined whether HBV activates NF- $\kappa \mathrm{B}$ in the presence of TNF- $\alpha$ and/or IL- $1 \beta$. We 
also examined the effects of HBV with or without TNF on human genes involved in metabolic pathways.

\section{Materials and methods}

Plasmids. The plasmid pCXN2 was kindly provided by Professor J. Miyazaki (17). The plasmid pCXN2-HBx was prepared as previously described (18). The plasmids pCMVHBV and pHBV were gratefully received from Professor A. McLachlan (19). The reporter plasmids pIGFBP1-luc and pNF- $\kappa$ B-luc were purchased from Abcam (Tokyo, Japan) and Agilent Technologies (Tokyo, Japan), respectively.

Cell culture. The human hepatoma cell lines HepG2, HepG2.2.15 and Huh7, which have been used in our laboratory $(16,20)$, and the immortalized human hepatocyte (IHH) cell line (kindly provided by Professor R. Ray) (21) were cultured in Dulbecco's modified Eagle's medium (DMEM) (Sigma, St. Louis, MO, USA) supplemented with $10 \%$ fetal calf serum (FCS) at $37^{\circ} \mathrm{C}$ and $5 \% \mathrm{CO}_{2}$. PXB cells, fresh hepatocyte cells from chimeric mice with transplanted human hepatocytes, were purchased from PhoenixBio Co., Ltd. (Higashihiroshima, Japan) (22). PXB cells were infected with HBV genotype C strain as previously described (22).

RNA extraction, cDNA synthesis and PCR array. HepG2 and HepG2.2.15. cells with or without $0.1 \mu \mathrm{g} / \mathrm{ml} \mathrm{TNF}$ were seeded into 6-well plates. After $48 \mathrm{~h}$, total cellular RNA was extracted using the RNeasy Mini kit(Qiagen,Hilden, Germany) according to the manufacturer's instructions. RNA samples were eluted in $60 \mu \mathrm{l}$ elution buffer and quantified using a NanoDrop Lite spectrophotometer (Thermo Fisher Scientific, Madison, WI, USA), and were then stored at $-80^{\circ} \mathrm{C}$ until use. cDNA was synthesized from $25 \mathrm{ng}$ total RNA using the SABiosciences $\mathrm{RT}^{2}$ First Strand kit (Qiagen) according to the manufacturer's instructions. Following a denaturation step at $42^{\circ} \mathrm{C}$ for $5 \mathrm{~min}$, RNA was reverse transcribed to single-stranded cDNA using RT Enzyme Mix provided by the RT ${ }^{2}$ First Strand kit (Qiagen). The reverse transcription reaction was performed in a total volume of $20 \mu \mathrm{l}$ at $42^{\circ} \mathrm{C}$ for $15 \mathrm{~min}$ and $95^{\circ} \mathrm{C}$ for $5 \mathrm{~min}$. For the purpose of determining the expression of mRNAs associated with metabolic-related gene expression, quantitative PCR was performed using $\mathrm{RT}^{2}$ SYBR-Green/ROX qPCR Master mix (PAHS-157Z, RT $^{2}$ Profiler $^{\mathrm{TM}}$ PCR Array Human Fatty Liver, Qiagen). The PCR array combines the quantitative performance of SYBR-Green-based real-time PCR with the multiple gene profiling capabilities of a microarray. Ninety-six-well plates containing gene-specific primer sets for 84 metabolic-related genes, 5 housekeeping genes and 2 negative controls were used. After performing thermal cycling, amplification data were gathered using the ABI 7300 instrument for RT2 Profiler $^{\mathrm{TM}}$ PCR arrays (Qiagen). Gene expression was normalized to internal controls (housekeeping genes) to determine the fold change in gene expression between the test sample (HepG2.2.15 with or without TNF) and the control sample (HepG2 with or without TNF) using the $\Delta \Delta \mathrm{CT}$ (comparative cycle threshold) method (23).

Transfection and reporter assay. Approximately $1.0 \times 10^{5}$ cells were seeded into 6-well plates (AGC Techno Glass, Shizuoka,
Japan) $24 \mathrm{~h}$ prior to transfection. For the purpose of detecting the relative activity of NF- $\mathrm{KB}$ in Huh7 and IHH cells, the cells were co-transfected with $0.3 \mu \mathrm{g} \mathrm{pHBV} / \mathrm{pCXN} 2-\mathrm{HBx}$ and $0.1 \mu \mathrm{g} \mathrm{pNF}-\kappa \mathrm{B}-l \mathrm{luc}$, respectively in Effectene transfection reagent (Qiagen). The cells were treated for $24 \mathrm{~h}$ with $10 \mathrm{ng} / \mathrm{ml} \mathrm{TNF-} \alpha$ and/or $10 \mathrm{ng} / \mathrm{ml} \mathrm{IL}-1 \beta$, with or without $1 \mu \mathrm{M}$ MG132 (Z-Leu-Leu-Leu-al; Sigma-Aldrich) after transfection. For detecting the relative activity of IGFBP1-promoter in HepG2 cells, the cells were cotransfected with $0.2 \mu \mathrm{g}$ pCXN2, pCXN2HBX, pCMVHBV or pHBV and $0.1 \mu \mathrm{g}$ pIGFBP1-luc in Effectene transfection reagent (Qiagen). At $30 \mathrm{~h}$ post-transfection, the cells were lysed with reporter lysis buffer (Promega, Madison, WI, USA) and the luciferase activities were determined using a luminometer (Luminescencer-JNR II AB-2300; ATTO Bio Instrument, Tokyo, Japan) as described previously (23).

Antibodies and western blot analysis. IL-1R2 (ab97388) was purchased from Abcam. TNF-R1 (H-5) (sc-8436), TNF-R2 (D-2) (sc-8041), IL-1R1 (N-20) (sc-688), XBP1 (M-186) (sc-7160), IGFBP1 (H-120) (sc-13097), GAPDH (4G5) (sc-51906) were all purchased from Santa Cruz Biotechnology, Inc. (Santa Cruz, CA, USA).

The cells were seeded into 6-well plates and cell lysates were prepared after $48 \mathrm{~h}$ using $50 \mu \mathrm{l}$ sodium dodecyl sulfate sample buffer. After sonication, the lysed proteins were subjected to sodium dodecyl sulfate-polyacrylamide gel electrophoresis (SDS-PAGE) on 5-20\% polyacrylamide gels and transferred onto polyvinylidene difluoride membranes (ATTO Bio Instrument) for western blot analysis. The membranes were incubated with primary specific antibodies. After washing, the membranes were incubated with secondary horse-radish peroxidase-conjugated antibodies. Signals were detected by means of enhanced chemiluminescence (GE Healthcare, Tokyo, Japan) and scanned using an image analyzer (LAS-4000; FujiFilm, Tokyo, Japan).

Statistical analysis. Results are expressed as the means \pm SD. Comparisons were performed using the Student's t-test. All P-values were two-tailed, and a P-value $<0.05$ was considered to indicate a statistically significant difference.

\section{Results}

Human hepatocytes express TNF receptors and IL-1 $1 \beta$ receptors. Firstly, we examined the expression of TNF receptors [TNF receptor (TNF-R)1 and TNF-R2] and IL- $1 \beta$ receptors [IL-1 receptor (IL-1R)2 and IL-1R2] at the protein level in human hepatocytes (Fig. 1). Human hepatoma HepG2, HepG2.2.15 and Huh7 cells and IHH cells expressed both TNF receptors and IL-1 $1 \beta$ receptors.

Activation of $N F-\kappa B$ by cooperation between $H B V$ and TNF in human hepatocytes. It is well known that HBV infection may upregulate the production of inflammatory cytokines (5-7). However, the effect of HBV and TNF and/or TNF/IL-1 $\beta$ on NF- $\kappa \mathrm{B}$ activation in hepatocytes remains unclear. Thus, we next examined whether HBV enhanced NF- $\mathrm{KB}$ activation in the presence of TNF/IL-1 $\beta$ in human hepatoma Huh7 cells (Fig. 2A) and in IHH cells (Fig. 2B). The reporter gene

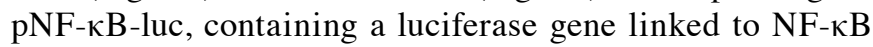




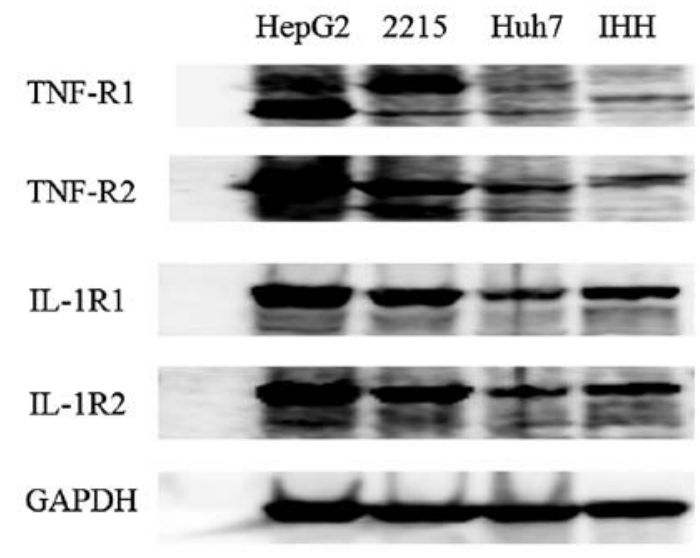

Figure 1. Tumor necrosis factor (TNF) receptor and interleukin-1 $\beta$ (IL-1 $\beta$ ) receptor expression in human hepatocytes. TNF receptor (TNF-R)1, TNF-R2, IL-1 receptor (IL-1R)1, IL-1R2 and GAPDH protein expression were examined. Total cell lysates $(5 \mu \mathrm{g})$ of HepG2, HepG2.2.15 (2215), Huh7 and IHH were subjected to 5-20\% SDS-PAGE for western blot analysis with specific antibodies against TNF-R1, TNF-R2, IL-1R1, IL-1R2 and GAPDH.

response elements, was transfected into Huh7 or IHH cells, together with pHBV. After $24 \mathrm{~h}$, the cells were treated with $10 \mathrm{ng} / \mathrm{ml} \mathrm{TNF}-\alpha$ and/or $10 \mathrm{ng} / \mathrm{ml} \mathrm{IL}-1 \beta$, or left untreated. Reporter assays were performed $6 \mathrm{~h}$ later. In the Huh7 cells, reporter assays revealed that the treatment with TNF- $\alpha$ and/or IL-1 $\beta$ increased reporter activity compared with the untreated control (Fig. 2A), and that reporter activities were higher in the presence of HBV than in its absence (Fig. 2A). In the IHH cells, reporter assays revealed that the treatment with TNF- $\alpha$, with or without IL-1 $\beta$, increased reporter activity compared with the untreated control (Fig. 2B), and that reporter activities were higher in the presence of HBV than in its absence (Fig. 2B).

Activation of $N F-\kappa B$ by cooperation between $H B V X$ protein $(H B x)$ and TNF in human hepatocytes. HBx protein may activate a cellular transcription factor in hepatocytes (18). However, the effect of HBx and TNF and/or TNF/IL-1 $\beta$ on NF- $\kappa B$ activation in hepatocytes remains unclear. We therefore examined whether HBx enhanced $\mathrm{NF}-\kappa \mathrm{B}$ activation in the presence of TNF/IL-1 $\beta$ in human hepatoma Huh7 cells (Fig. 3A) and in IHH cells (Fig. 3B). The reporter gene pNF- $\mathrm{kB}-\mathrm{luc}$, containing a luciferase gene linked to NF-кB response elements was transfected into Huh7 or IHH cells, together with pCXN2-HBx. After $24 \mathrm{~h}$, the cells were treated with $10 \mathrm{ng} / \mathrm{ml} \mathrm{TNF}$ and/or $10 \mathrm{ng} / \mathrm{ml} \mathrm{IL}-1 \beta$, or left untreated. Reporter assays were performed $6 \mathrm{~h}$ later. In the Huh7 cells, reporter assays revealed that treatment with TNF and/or IL-1 $\beta$ increased reporter activity compared with the untreated control (Fig. 3A), and that reporter activities were higher in the presence of HBx than those in the absence of HBx (Fig. 3A). In the IHH cells, reporter assays revealed that treatment with TNF with or without IL-1 $\beta$, increased reporter activity compared with the untreated control (Fig. 3B), and that reporter activities were higher in the presence of $\mathrm{HBx}$ than in its absence (Fig. 3B).

MG132 blocks the activation of NF- $\kappa B$ by $H B x$. The proteasome inhibitor MG132, which blocks the degradation of IкB, may block NF- $\kappa \mathrm{B}$ activation. We found that $1 \mu \mathrm{M}$ MG132 blocked NF- $\mathrm{KB}$ activation by HBx with or without TNF in the Huh7 cells (Fig. 4A), and that $1 \mu \mathrm{M}$ MG132 blocked NF- $\kappa \mathrm{B}$ activation through the cooperation between $\mathrm{HBx}$ and TNF in Huh7 cells (Fig. 4B). These results suggested that proteasome pathways were involved in the HBx-mediated activation of NF-kB by TNF.

HBV enhances IGFBPI expression and HBx enhances IGFBPI promoter activity. It has been reported that TNF- $\alpha$ increased IGFBP1 production in HepG2 cells and that pyrrolidine dithiocarbamate (PDTC), an inhibitor of NF- $\mathrm{\kappa B}$ activation, reduced IGFBP1 production induced by cytokines (24). We examined the effect of HBV on IGFBP1 expression. We extracted cell lysates from PXB cells infected with or without HBV genotype $\mathrm{C}$ strain at day 27 post-infection because both HBV DNA and HBsAg were positive at this point (22). PXB cells may
A

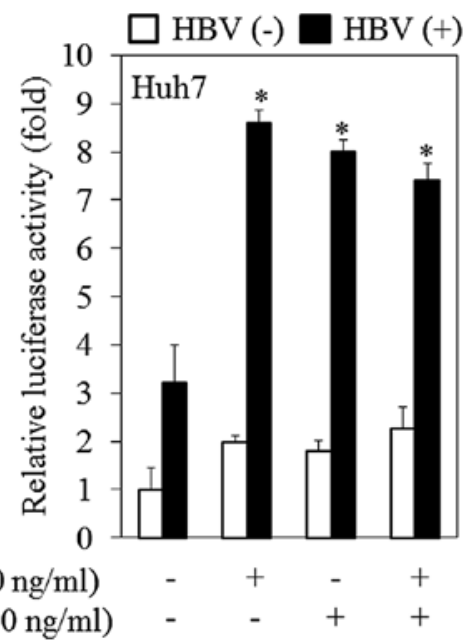

B

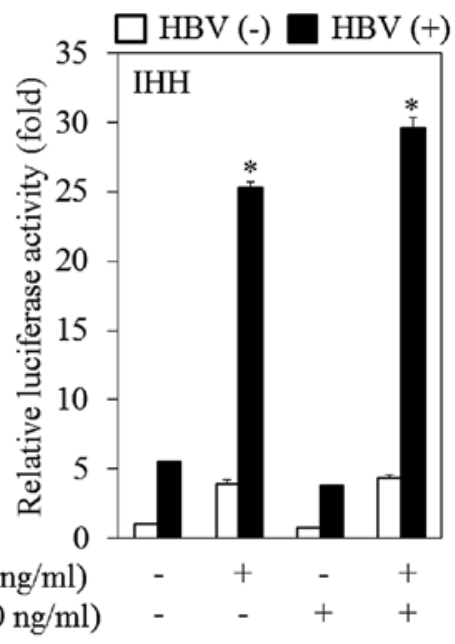

Figure 2. Nuclear factor- $\kappa \mathrm{B}(\mathrm{NF}-\kappa \mathrm{B})$ activity is enhanced by cooperation between hepatitis B virus (HBV) and tumor necrosis factor (TNF)/interleukin (IL)-1 $\beta$ in hepatocytes. (A) Huh7 cells and (B) IHH cells. Luciferase activity was measured, and it is shown as the mean value from 3 independent experiments (means \pm SD). Relative luciferase activity of untreated control was set at 1 . Black columns and white columns indicate the results from transfection with and without $\mathrm{pHBV}$, respectively. ${ }^{*} \mathrm{P}<0.05$ vs. control. 
A

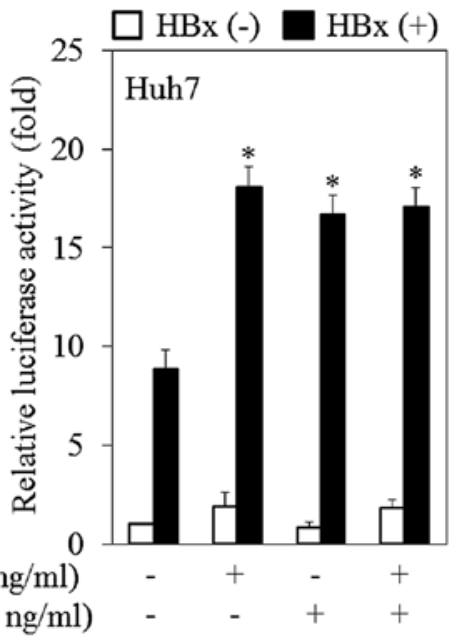

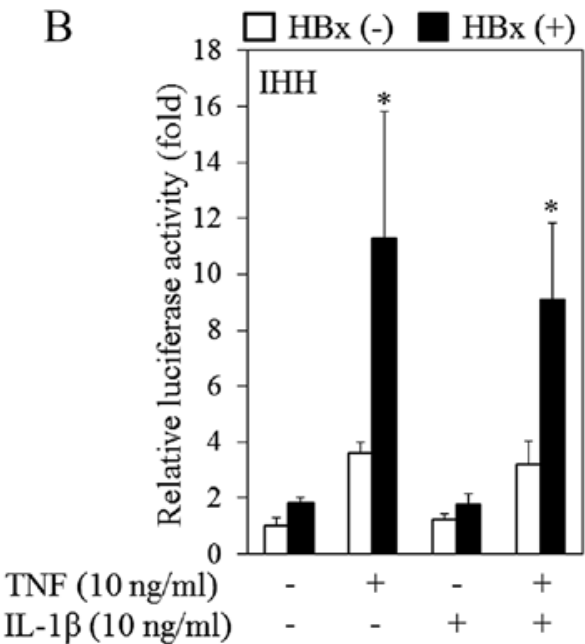

Figure 3. Nuclear factor- $\mathrm{\kappa B}(\mathrm{NF}-\mathrm{\kappa B})$ activity is enhanced by the cooperation between HBV X protein (HBx) and tumor necrosis factor (TNF)/interleukin (IL)-1 $\beta$ in hepatocytes. (A) Huh7 cells and (B) IHH cells. Luciferase activity was measured, and it is shown as the mean value from 3 independent experiments (means $\pm \mathrm{SD}$ ). Relative luciferase activity of untreated control was set at 1 . Black columns and white columns indicate the results from transfection with pCXN2-HBx or pCXN2, respectively. "P<0.05 vs. control.

A

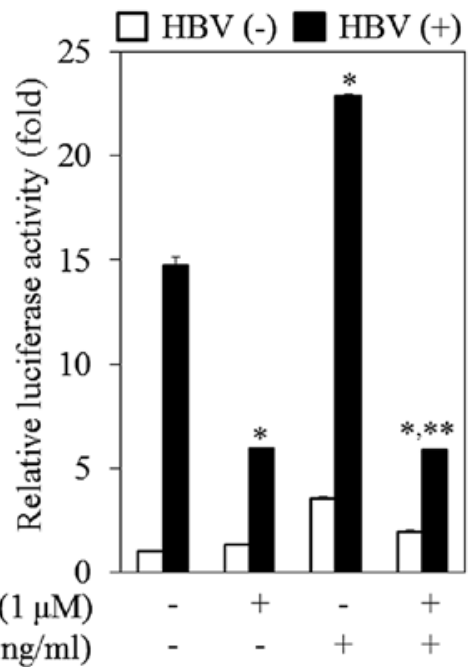

B

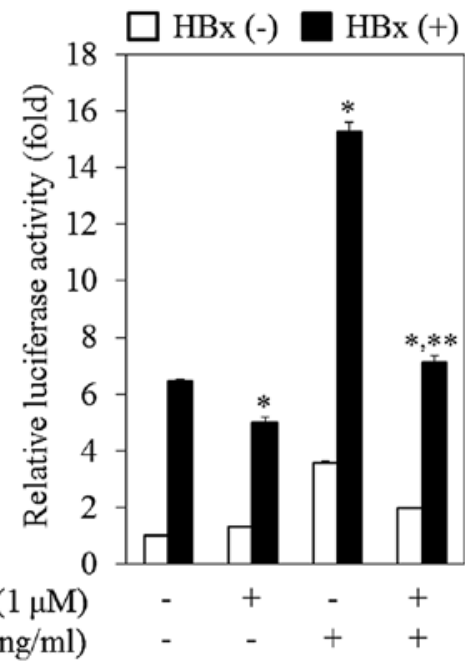

Figure 4. MG132 inhibits the activation of nuclear factor- $\kappa \mathrm{B}(\mathrm{NF}-\kappa \mathrm{B})$ activity enhanced by cooperation between hepatitis $\mathrm{B}$ virus $(\mathrm{HBV}) / \mathrm{HBV} \mathrm{X}$ protein $(\mathrm{HBx})$ and tumor necrosis factor (TNF) in Huh7 cells. (A) HBV. Black columns and white columns indicate the results from transfection with and without pHBV, respectively. (B) HBx. Black columns and white columns indicate the results from transfection with pCXN2-HBx and pCXN2, respectively. Luciferase activity was measured, and it is shown as the mean value from 3 independent experiments (means \pm SD). Relative luciferase activity of untreated control was set at 1 . ${ }^{*} \mathrm{P}<0.05$ vs. control; ${ }^{* *} \mathrm{P}<0.05$ vs. TNF.

support HBV replication (22). Total cell lysates were subjected to SDS-PAGE for western blot analysis with specific antibodies against IGFBP1 and tubulin. We observed that IGFBP1 expression was enhanced in the HBV-infected PXB cells, compared with the uninfected PXB cells (Fig. 5A). Reporter assays revealed that $\mathrm{HBx}$ enhanced IGFBP1 promoter activity in HepG2 cells (Fig. 5B). This enhancement of IGFBP1 promoter activity induced by $\mathrm{HBx}$ was increased $\sim 1$-f-fold by the addition of TNF (data not shown). These results suggest that $\mathrm{HBV}$ infection results in the activation of IGFBP1, one of the important genes involved in the insulin signaling pathway.

Expression of metabolic pathway-associated genes is modulated in HBV-infected hepatocytes. Thus, IGFBP1, which is a NF-кB-dependent metabolic pathway-associated gene, was upregulated by HBV. We further examined the effects of HBV on the expression of metabolic pathway-associated genes. To gain mechanistic insights into the effects of HBV on metabolic pathway-associated genes, we used a pathway-specific gene array to identify HBV target genes in HepG2.2.15 cells compared with HepG 2 control cells, in the presence or absence of TNF (Fig. 6). HepG2.2.15 cells may produce infectious HBV virions and HepG2 is its parental cell line (16). We extracted total RNA from HepG2 and HepG2.2.15 cells in order to study the effect of HBV on metabolic pathway-associated gene expression using a human fatty liver PCR array.

In the absence of TNF, a total of 22 genes were significantly upregulated in HepG2.2.15 cells $(\mathrm{P}<0.05)$. In the presence of TNF, a total of 40 genes were significantly upregulated in HepG2.2.15 cells $(\mathrm{P}<0.05)$. Among them, there were 17 


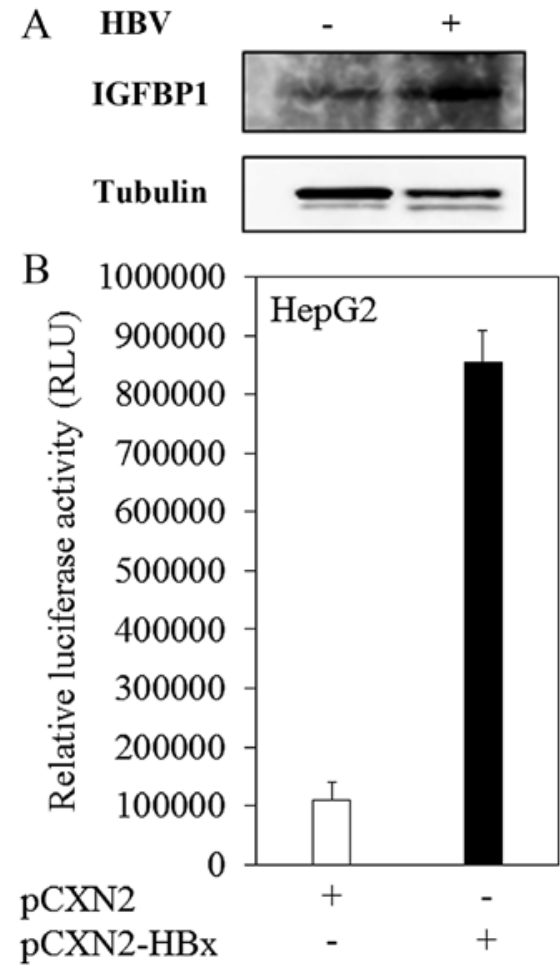

Figure 5. Hepatitis B virus (HBV) enhances insulin-like growth factor binding protein-1 (IGFBP1) expression in human hepatocytes. (A) IGFBP1 expression in PXB cells infected with or without HBV genotype C. Total cell lysates $(5 \mu \mathrm{g})$ were subjected to 5-20\% SDS-PAGE for western blot analysis with specific antibodies against IGFBP1 and tubulin. (B) HBx enhanced IGFBP1 promoter activity in HepG2 cells in the presence of HBx (black column) or in its absence (white column).

shared genes identified in the absence and presence of TNF [apolipoprotein B (APOB); apolipoprotein A-I (APOA1); solute carrier family 2 (facilitated glucose transporter), member 2 (SLC2A2); pyruvate kinase, liver and RBC (PKLR); acyl-CoA synthetase long-chain family member 5 (ACSL5); apolipoprotein C-III (APOC3); nuclear receptor subfamily 1, group $\mathrm{H}$, member 4 (NR1H4); retinol binding protein 4 , plasma (RBP4); apolipoprotein E (APOE); insulin-like growth factor binding protein 1 (IGFBP1); phosphoinositide3-kinase, regulatory subunit 1 (PIK3R1); glycerol kinase (GK); diacylglycerol O-acyltransferase 2 (DGAT2); X-box binding protein 1 (XBP1); serpin peptidase inhibitor, clade E (nexin, plasminogen activator inhibitor type 1), member 1(SERPINE1); nuclear receptor subfamily 1 , group $\mathrm{H}$, member 4 (NR1H3); peroxisome proliferator-activated receptor alpha (PPARA)] Several genes associated with insulin and adipokine signaling pathways, such as PPARA, IGFBP1 and PIK3R1, were activated. The endoplasmic reticulum stress gene XBP1 was also upregulated. Notably, we observed upregulation of other metabolic pathway-associated genes in the HepG2.2.15 cells. On the other hand, none were significantly downregulated in HepG2.2.15 cells in the absence of TNF, and 6 genes [CCAAT/enhancer binding protein (C/EBP), beta (CEBPB); suppressor of cytokine signaling 3 (SOCS3); sterol regulatory element binding transcription factor (SREBF)2; fatty acid binding protein 3, muscle and heart (FABP3); SREBF1; and IL-6] were significantly downregulated in HepG2.2.15 cells treated with TNF (data not shown).

\section{Discussion}

In the present study, we demonstrated the cooperative effects of HBV and TNF on NF- $\mathrm{KB}$ activation in human hepatocytes. HBx appears to be involved in the activation of NF- $\mathrm{kB}$. The activation of NF- $\mathrm{KB}$ was inhibited by the proteasome inhibitor MG132, suggesting that proteasome pathways were involved in the HBV/HBx-mediated activation of NF- $\mathrm{KB}$. We also observed that IGFBP1 expression was enhanced in human hepatocytes infected with HBV and that HBV enhanced the expression of metabolic pathway-associated genes in the presence or absence of TNF.

TNF- $\alpha$ is at present considered as the pro-inflammatory cytokine that introduced the link between inflammation, obesity and insulin resistance $(9,10,25,26)$. During the search for the underlying mechanisms, researchers studied various signaling pathways and transcription factors and identified the IKK $\beta$ pathway as a target for TNF- $\alpha$-induced insulin resistance (27). Two other studies have also demonstrated the association between IKK $\beta$ expression in the liver and insulin resistance $(28,29)$. In terms of these studies, our findings suggested that the cooperative effects of HBV and TNF on NF- $\kappa \mathrm{B}$ activation may have induced insulin resistance by upregulating IGFBP1. On the other hand, considerable evidence has been generated regarding the roles of the IL-1 family of cytokines in metabolic inflammation $(30,31)$. IL-1 $\beta$, similar to other pro-inflammatory stimuli, is capable of reducing IRS1 expression at a transcriptional level through an ERK-dependent mechanism (32). Both IL-1 $\alpha$ - and IL-1 $\beta$-deficient mice are almost entirely protected from liver inflammation following diet-induced steatosis suggesting that these pro-inflammatory IL-1 cytokines may be crucially involved in the development of liver inflammation (33). Lang et al have demonstrated that, in human hepatoma cells, IL-1 and TNF- $\alpha$ produce dose-dependent increases in IGFBP1 protein release and IGFBP1 mRNA expression and that the increased rate of IGFBP1 synthesis is due primarily to the stimulation of transcription (24).

HCC develops from a background of chronic liver diseases. Common causes include viral hepatitis [HBV or hepatitis C virus (HCV)], alcoholic liver diseases and autoimmune liver diseases. Emerging evidence suggests an association between metabolic factors and the risk of HCC in both developing and developed countries (34). Experimental evidence suggests that HBx promotes cell growth and HCC by upregulating lipogenic gene expression (35-37). Na et al has used transgenic mice and cell lines to show that HBx enhances the expression of liver $\mathrm{X}$ receptor (LXR) and its lipogenic target genes, such as sterol regulatory element-binding protein 1 (SREBP1), FAS and PPAR, which are accompanied by lipid droplet accumulation and eventually lead to HCC (35). Another study has shown that HBx induced the activation of SREBP1 through the PI3K-Akt pathway (38). The tumorigenic effects of insulin resistance may be mediated directly by insulin signaling, or indirectly through changes in endogenous hormone metabolism. In particular, metabolic pathway-associated genes such as IGF1, which undergo bioactive modulation by IGFBP1, may be involved. To the best of our knowledge, there do not appear to have been any metabolic studies comparing HBV-positive and HBV-negative subjects and furthermore, there are no specific 


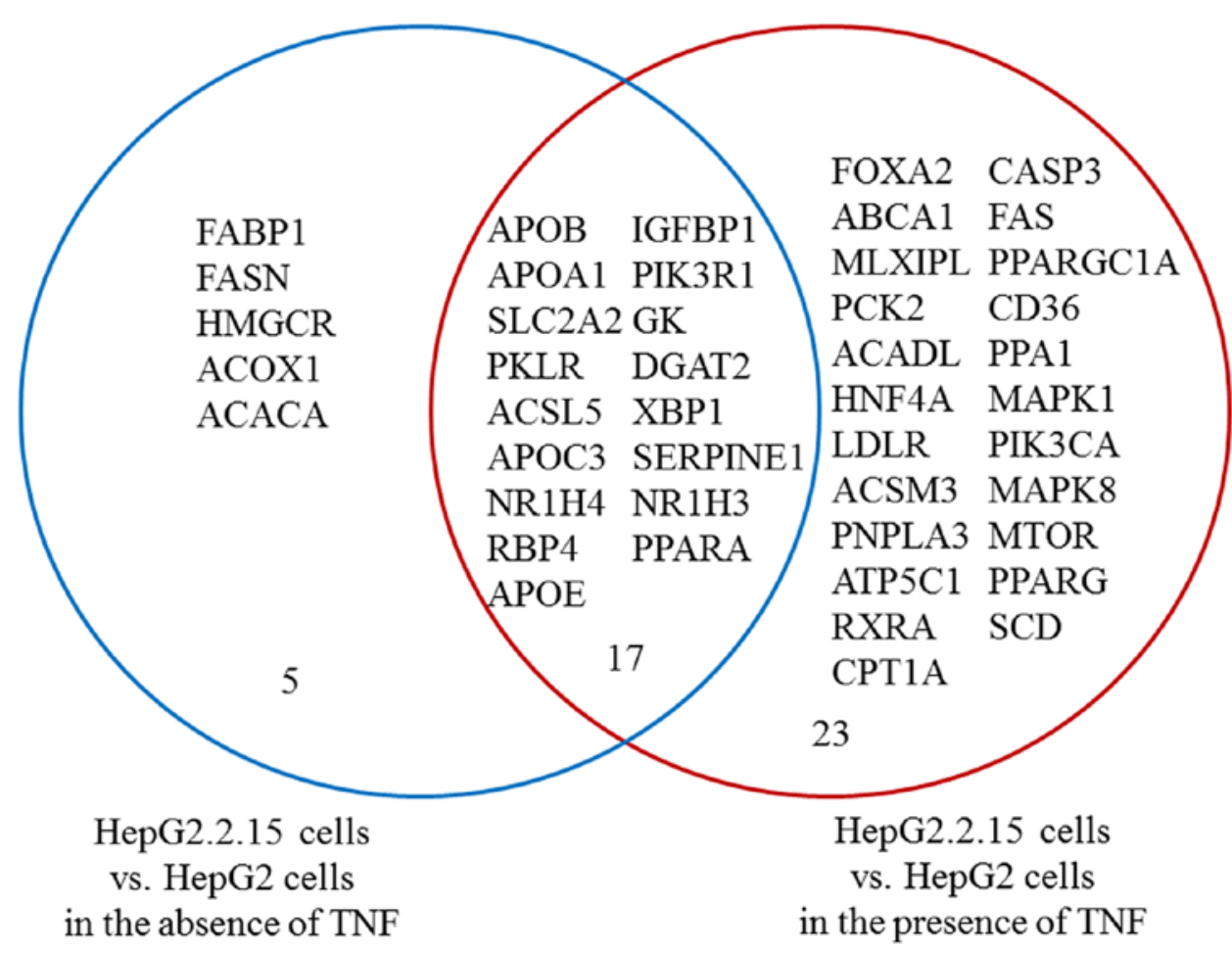

Figure 6. Venn diagram representing unique and shared metabolic pathway-associated genes differentially expressed in HepG2.2.15 (vs. HepG2) with or without tumor necrosis factor (TNF). Genes indicated as $\mathrm{P}<0.05$. Total RNAs were extracted from HepG2 and HepG2.2.15 treated with or without TNF. Following the synthesis of cDNA, human fatty liver PCR arrays were performed. Data were analyzed with RT ${ }^{2}$ profiler PCR array data analysis software. Fatty acid binding protein 1, liver (FABP1); fatty acid synthase (FASN); 3-hydroxy-3-methylglutaryl-CoA reductase (HMGCR); acyl-CoA oxidase 1, palmitoyl (ACOX1); acetyl-CoA carboxylase alpha (ACACA); apolipoprotein B (APOB); apolipoprotein A-I (APOA1); solute carrier family 2 (facilitated glucose transporter), member 2 (SLC2A2); pyruvate kinase, liver and RBC (PKLR); acyl-CoA synthetase long-chain family member 5 (ACSL5); apolipoprotein C-III (APOC3); nuclear receptor subfamily 1, group H, member 4 (NR1H4); retinol binding protein 4, plasma (RBP4); apolipoprotein E (APOE); insulin-like growth factor binding protein 1 (IGFBP1); phosphoinositide-3-kinase, regulatory subunit 1 (PIK3R1); glycerol kinase (GK); diacylglycerol O-acyltransferase 2 (DGAT2); X-box binding protein 1 (XBP1); serpin peptidase inhibitor, clade E (nexin, plasminogen activator inhibitor type 1), member 1 (SERPINE1); nuclear receptor subfamily 1, group $\mathrm{H}$, member $3(\mathrm{NR} 1 \mathrm{H} 3)$; peroxisome proliferator-activated receptor alpha (PPARA); forkhead box A2 (FOXA2); ATP-binding cassette, sub-family A (ABC1), member 1 (ABCA1); MLX interacting protein-like (MLXIPL); phosphoenolpyruvate carboxykinase 2 (mitochondrial) (PCK2); acylCoA dehydrogenase, long chain (ACADL); hepatocyte nuclear factor 4, alpha (HNF4A); low density lipoprotein receptor (LDLR); acyl-CoA synthetase medium-chain family member 3 (ACSM3); patatin-like phospholipase domain containing 3 (PNPLA3); ATP synthase, $\mathrm{H}^{+}$transporting, mitochondrial F1 complex, $\gamma$ polypeptide 1 (ATP5C1); retinoid X receptor alpha (RXRA); carnitine palmitoyltransferase 1A (liver) (CPT1A); caspase-3, apoptosis-related cysteine peptidase (CASP3); Fas cell surface death receptor (FAS); peroxisome proliferator-activated receptor gamma, coactivator 1 alpha (PPARGC1A); CD36 molecule (thrombospondin receptor) (CD36); pyrophosphatase (inorganic) 1 (PPA1); mitogen-activated protein kinase 1 (MAPK1); phosphatidylinositol4,5-bisphosphate 3-kinase, catalytic subunit alpha (PIK3CA); mitogen-activated protein kinase 8 (MAPK8); mechanistic target of rapamycin (serine/threonine kinase) (MTOR); peroxisome proliferator-activated receptor gamma (PPARG); stearoyl-CoA desaturase (delta-9-desaturase) (SCD).

biomarkers for predicting HCC development in HBV-positive patients with or without cirrhosis. Our results also indicated that the cooperative effect of HBV and TNF on the expression of metabolic pathway-associated genes, which potentially play important roles in the activation of metabolic pathways, may shed light on the metabolic studies in HBV-induced HCC.

The transcription factor PPARG is an important regulator of hepatic lipid metabolism. Degenhardt et al (39) have demonstrated that the mRNA expression of IGFBP1 is under the primary control of PPARG ligands by identifying PPAR response elements (PPREs) located within IGFBP1, in human HCC cells and in normal mouse liver. The results of our metabolic pathway-associated gene expression PCR array (Fig. 6) indicated that PPARG was significantly upregulated by HBV and TNF stimulation (2.36- vs. 1.90-fold without TNF), suggesting that HBV and TNF upregulated IGFBP1 expression through the upregulation of PPARG expression.

In conclusion, the cooperative effects of HBV and TNF may play important roles in the activation of NF- $\mathrm{KB}$ and the expression of metabolic pathway-associated genes including IGFBP1. These results suggest that metabolic factors may also modify HBV-associated diseases as well as HCV $(40,41)$.

\section{Acknowledgements}

The present study was supported by a KAKEN Grant-in-Aid for Scientific Research from the Ministry of Education, Culture, Sports, Science, and Technology of Japan (no. 20345002). The authors thank Professor J. Miyazaki and Professor A. McLachlan for providing plasmids, and Professor R. Ray for providing IHH cells.

\section{References}

1. de Martel C, Maucort-Boulch D, Plummer M and Franceschi S: World-wide relative contribution of hepatitis $\mathrm{B}$ and $\mathrm{C}$ viruses in hepatocellular carcinoma. Hepatology 62: 1190-1200, 2015.

2. McMahon BJ: Chronic hepatitis B virus infection. Med Clin North Am 98: 39-54, 2014. 
3. Khalili M, Lombardero M, Chung RT, Terrault NA, Ghany MG, Kim WR, Lau D, Lisker-Melman M, Sanyal A and Lok AS; HBRN: Diabetes and prediabetes in patients with hepatitis B residing in North America. Hepatology 62: 1364-1374, 2015.

4. Kaneko M, Watashi K, Kamisuki S, Matsunaga H, Iwamoto M, Kawai F, Ohashi H, Tsukuda S, Shimura S, Suzuki R, et al: A novel tricyclic polyketide, vanitaracin A, specifically inhibits the entry of hepatitis B and D viruses through targeting NTCP. J Virol 89: 11945-11953, 2015

5. Lau JY, Sheron N, Nouri-Aria KT, Alexander GJ and Williams R: Increased tumor necrosis factor-alpha receptor number in chronic hepatitis B virus infection. Hepatology 14: 44-50, 1991.

6. González-Amaro R, García-Monzón C, García-Buey L, Moreno-Otero R, Alonso JL, Yagüe E,Pivel JP, López-Cabrera M, Fernández-Ruiz E and Sánchez-Madrid F: Induction of tumor necrosis factor alpha production by human hepatocytes in chronic viral hepatitis. J Exp Med 179: 841-848, 1994.

7. Geneva-Popova M and Murdjeva M: Study on proinflammatory cytokines (IL-1 beta, IL-6, TNF-alpha) and IL-2 in patients with acute hepatitis B. Folia Med (Plovdiv) 41: 78-81, 1999.

8. Daniels HM, Meager A, Eddleston AL, Alexander GJ and Williams R: Spontaneous production of tumour necrosis factor alpha and interleukin-1 beta during interferon-alpha treatment of chronic HBV infection. Lancet 335: 875-877, 1990.

9. Wieser V, Moschen AR and Tilg H: Inflammation, cytokines and insulin resistance: a clinical perspective. Arch Immunol Ther Exp (Warsz) 61: 119-125, 2013

10. Mehta NN, McGillicuddy FC, Anderson PD, Hinkle CC, Shah R Pruscino L, Tabita-Martinez J, Sellers KF, Rickels MR and Reilly MP: Experimental endotoxemia induces adipose inflammation and insulin resistance in humans. Diabetes 59: 172-181, 2010.

11. Sasaki Y: Insulin resistance and hepatocarcinogenesis. Clin J Gastroenterol 3: 271-278, 2010.

12. Karabulut S, Duranyıldız D, Tas F, Gezer U, Akyüz F, Serilmez M Ozgür E, Yasasever CT, Vatansever S and Aykan NF: Clinical significance of serum circulating insulin-like growth factor-1 (IGF-1) mRNA in hepatocellular carcinoma. Tumour Biol 35: 2729-2739, 2014

13. Hwang DL, Huang SP, Lan WS and Lee PD: Elevated insulin, proinsulin and insulin-like growth factor-binding protein-1 in liver disease. Growth Horm IGF Res 13: 316-321, 2003.

14. Dai B, Ruan B, Wu J, Wang J, Shang R, Sun W, Li X, Dou K, Wang $\mathrm{D}$ and $\mathrm{Li}$ Y: Insulin-like growth factor binding protein-1 inhibits cancer cell invasion and is associated with poor prognosis in hepatocellular carcinoma. Int J Clin Exp Pathol 7: 5645-5654, 2014.

15. Cao Y, Nimptsch K, Shui IM, Platz EA, Wu K, Pollak MN, Kenfield SA, Stampfer MJ and Giovannucci EL: Prediagnostic plasma IGFBP-1, IGF-1 and risk of prostate cancer. Int J Cancer 136: 2418-2426, 2015.

16. Wu S, Kanda T, Imazeki F, Arai M, Yonemitsu Y, Nakamoto S, Fujiwara K, Fukai K, Nomura F and Yokosuka O: Hepatitis B virus e antigen downregulates cytokine production in human hepatoma cell lines. Viral Immunol 23: 467-476, 2010.

17. Niwa H, Yamamura K and Miyazaki J: Efficient selection for high-expression transfectants with a novel eukaryotic vector. Gene 108: 193-199, 1991

18. Kanda T, Yokosuka O, Imazeki F, Yamada Y, Imamura T, Fukai K, Nagao K and Saisho H: Hepatitis B virus X protein $(\mathrm{HBx})$-induced apoptosis in $\mathrm{HuH}-7$ cells: influence of HBV genotype and basal core promoter mutations. Scand J Gastroenterol 39: 478-485, 2004.

19. Oropeza CE, Li L and McLachlan A: Differential inhibition of nuclear hormone receptor-dependent hepatitis B virus replication by the small heterodimer partner. J Virol 82: 3814-3821, 2008.

20. Blight KJ, Kolykhalov AA and Rice CM: Efficient initiation of HCV RNA replication in cell culture. Science 290: 1972-1974, 2000.

21. Ray RB, Meyer K and Ray R: Hepatitis C virus core protein promotes immortalization of primary human hepatocytes. Virology 271: 197-204, 2000.

22. Sasaki R, Kanda T, Wu S, Nakamoto S, Haga Y, Jiang X, Nakamura M, Shirasawa $\mathrm{H}$ and Yokosuka O: Association between hepatitis B virus and MHC class I polypeptide-related chain $\mathrm{A}$ in human hepatocytes derived from human-mouse chimeric mouse liver. Biochem Biophys Res Commun 464: $1192-1195,2015$
23. Wu S, Kanda T, Imazeki F, Nakamoto S, Tanaka T, Arai M, Roger T, Shirasawa H, Nomura F and Yokosuka O: Hepatitis B virus e antigen physically associates with receptor-interacting serine/threonine protein kinase 2 and regulates IL- 6 gene expression. J Infect Dis 206: 415-420, 2012.

24. Lang CH, Nystrom GJ and Frost RA: Regulation of IGF binding protein-1 in hep $\mathrm{G} 2$ cells by cytokines and reactive oxygen species. Am J Physiol 276: G719-G727, 1999.

25. Hotamisligil GS, Peraldi P, Budavari A, Ellis R, White MF and Spiegelman BM: IRS-1-mediated inhibition of insulin receptor tyrosine kinase activity in TNF-alpha- and obesity-induced insulin resistance. Science 271: 665-668, 1996.

26. Aguirre V, Uchida T, Yenush L, Davis R and White MF: The c-Jun $\mathrm{NH}(2)$-terminal kinase promotes insulin resistance during association with insulin receptor substrate-1 and phosphorylation of Ser(307). J Biol Chem 275: 9047-9054, 2000.

27. Yuan M, Konstantopoulos N, Lee J, Hansen L, Li ZW, Karin M and Shoelson SE: Reversal of obesity- and diet-induced insulin resistance with salicylates or targeted disruption of Ikkbeta. Science 293: 1673-1677, 2001.

28. Arkan MC, Hevener AL, Greten FR, Maeda S, Li ZW, Long JM, Wynshaw-Boris A, Poli G, Olefsky J and Karin M: IKK-beta links inflammation to obesity-induced insulin resistance. Nat Med 11: 191-198, 2005.

29. Cai D, Yuan M, Frantz DF, Melendez PA, Hansen L, Lee J and Shoelson SE: Local and systemic insulin resistance resulting from hepatic activation of IKK-beta and NF-kappaB. Nat Med 11: 183-190, 2005.

30. Donath MY and Shoelson SE: Type 2 diabetes as an inflammatory disease. Nat Rev Immunol 11: 98-107, 2011.

31. Stienstra R, Tack CJ, Kanneganti TD, Joosten LA and Netea MG: The inflammasome puts obesity in the danger zone. Cell Metab 15: 10-18, 2012.

32. He J, Usui I, Ishizuka K, Kanatani Y, Hiratani K, Iwata M, Bukhari A, Haruta T, Sasaoka $\mathrm{T}$ and Kobayashi M: Interleukin-1alpha inhibits insulin signaling with phosphorylating insulin receptor substrate-1 on serine residues in 3T3-L1 adipocytes. Mol Endocrinol 20: 114-124, 2006.

33. Kamari Y, Shaish A, Vax E, Shemesh S, Kandel-Kfir M, Arbel Y, Olteanu S, Barshack I, Dotan S, Voronov E, et al: Lack of interleukin-1 $\alpha$ or interleukin-1 $\beta$ inhibits transformation of steatosis to steatohepatitis and liver fibrosis in hypercholesterolemic mice. J Hepatol 55: 1086-1094, 2011.

34. Haga Y, Kanda T, Sasaki R, Nakamura M, Nakamoto S and Yokosuka O: Nonalcoholic fatty liver disease and hepatic cirrhosis: comparison with viral hepatitis-associated steatosis. World J Gastroenterol 21: 12989-12995, 2015.

35. Na TY, Shin YK, Roh KJ, Kang SA, Hong I, Oh SJ, Seong JK, Park CK, Choi YL and Lee MO: Liver X receptor mediates hepatitis B virus X protein-induced lipogenesis in hepatitis B virus-associated hepatocellular carcinoma. Hepatology 49: $1122-1131,2009$.

36. Wang Q, Zhang WY, Ye LH and Zhang XD: A mutant of HBx (HBxDelta127) promotes hepatoma cell growth via sterol regulatory element binding protein 1c involving 5-lipoxygenase. Acta Pharmacol Sin 31: 367-374, 2010.

37. Kim JY, Song EH, Lee HJ, Oh YK, Choi KH, Yu DY, Park SI, Seong JK and Kim WH: HBx-induced hepatic steatosis and apoptosis are regulated by TNFR1- and NF-kappaB-dependent pathways. J Mol Biol 397: 917-931, 2010

38. Kim KH, Shin HJ, Kim K, Choi HM, Rhee SH, Moon HB Kim HH, Yang US, Yu DY and Cheong J: Hepatitis B virus X protein induces hepatic steatosis via transcriptional activation of SREBP1 and PPARgamma. Gastroenterology 132: 1955-1967, 2007.

39. Degenhardt T, Matilainen M, Herzig KH, Dunlop TW and Carlberg C: The insulin-like growth factor-binding protein 1 gene is a primary target of peroxisome proliferator-activated receptors. J Biol Chem 281: 39607-39619, 2006.

40. Banerjee S, Saito K, Ait-Goughoulte M, Meyer K, Ray RB and Ray R: Hepatitis $\mathrm{C}$ virus core protein upregulates serine phosphorylation of insulin receptor substrate-1 and impairs the downstream akt/protein kinase B signaling pathway for insulin resistance. J Virol 82: 2606-2612, 2008.

41. Bose SK, Shrivastava S, Meyer K, Ray RB and Ray R: Hepatitis C virus activates the mTOR/S6K1 signaling pathway in inhibiting IRS-1 function for insulin resistance. J Virol 86: 6315-6322, 2012. 